2 Bell NH, Stern PH, Pantzer E, Sinha TK, De Luca HF. Evidence that increased circulating $1 \propto 25$ dihydroxyvitamin $\mathrm{D}$ is the probable cause for abnormal calcium metabolism in sarcoidosis. 7 Clin Invest 1979;64: 218-25.

${ }^{3}$ Bell NH, Epstein S, Stern PH. Hypercalcemia during long-term treatment with 1,25 -dihydroxyvitamin $\mathrm{D}_{3}$ in hypoparathyroidism. $N$ Engl $\mathcal{F} \mathrm{Med}$ $1979 ; 301: 1183-4$

${ }^{4}$ Lund Bj, Sorensen OH, Lund Bi, Bishop JE, Norman AW. Vitamin D metabolism in hypoparathyroidism. F Clin Endocrinol Metab 1980;51: 606-10.

${ }^{5}$ Clemens TL, Hendy GN, Papapoulos SE, Fraher LJ, Care AD, O'Riordan JLH. Measurement of 1,25 dihydroxycholecalciferol in man by radioimmunoassay. Clin Endocrinol (Oxf) 1979;11:225-34.

(Accepted 30 December 1982)

Metabolic Unit, Royal National Orthopaedic Hospital, Stanmore, Middlesex

T H MITCHELL, MRCP, senior registrar

T C B STAMP, FRCP, consultant physician

$M$ V JENKINS, PHD, biochemist

University Department of Medicine, Manchester

E B MAWER, PHD, senior lecturer

J L BERRY, PHD, biochemist

Correspondence to: Dr T C B Stamp.

\section{Salmonella gastroenteritis associated with erythema nodosum}

There are several well established causes of erythema nodosum, and two case reports of erythema nodosum occurring after salmonella gastroenteritis have suggested that this infection may be an additional cause. ${ }^{2}$ Both cases seem to have been isolated ones; admission to hospital was necessary in both.

In October 1981 an outbreak of Salmonella typhimurium gastroenteritis occurred in our practice, which affected over 700 patients and was bacteriologically proved in 440 . During this outbreak three cases of erythema nodosum were seen.

\section{Case reports}

Case 1-A 10 year old previously well girl developed diarrhoea. Stool culture was positive for $S$ typhimurium. She was not unduly ill and recovered quickly, but 14 days later she developed typical erythema nodosum on her legs, which gradually faded. No investigations were undertaken at this time, but the antistreptolysin $\mathrm{O}$ titre five months later was 240. HLA typing showed HLA-A2, B8, and B40.

Case 2-An 85 year old previously well woman developed diarrhoea from which $S$ typhimurium was cultured. Eleven days later she developed typical erythema nodosum on her legs and slightly on her arms. Her recovery from the illness was slow but complete. Antistreptolysin $\mathrm{O}$ titre five months later was 240 . HLA typing showed HLA-A3, A9, B7, and B12.

Case 3-A 50 year old woman developed diarrhoea from which $S$ typhimurium was cultured. Fifteen years previously she had undergone mitral valve plication for mitral stenosis. At the time of the thoracotomy a node biopsy had been diagnostic of sarcoidosis, and she had been treated with steroids for a short time thereafter. She was also asthmatic and was taking digoxin, bumetanide, and both salbutamol and beclomethasone inhalers. Nine days after the start of her diarrhoea she developed typical erythema nodosum on both legs, followed four days later by pain and swelling in one wrist and one knee. There was no generalised lymphadenopathy, and a chest $x$ ray film showed no hilar lymphadenopathy. Reactive arthritis was diagnosed and all symptoms gradually settled. The antistreptolysin $\mathrm{O}$ titre seven days after the rash developed was less than 160 , rising to 320 a month later. HLA typing showed HLA-A1, A11, B22, and B35.

\section{Comment}

Our practice is the only one serving the town, and no other case of erythema nodosum was seen at this time from a total practice population of 7100 . Concurrent streptococcal infection cannot be totally excluded in these three patients. Nevertheless, the close relation of erythema nodosum to the symptoms of salmonella gastroenteritis and the absence of other cases of erythema nodosum in patients who did not have gastroenteritis are further evidence in favour of $S$ typhimurium being a cause of erythema nodosum.
We thank Dr Clifford Eastmond, consultant rheumatologist, City Hospital Aberdeen, for his help and encouragement.

${ }^{1}$ Scott BB. Salmonella gastroenteritis-another cause of erythema nodosum. Br f Dermatol 1980;102:339.

2 Toribio N, Perez-Oliva N, Quinones PA, Tejerina JA. Eritema nudoso par Salmonlosis gastroenterica. Actas Dermosifiliogr 1981 ;72:473-4.

(Accepted 10 December 1982)

Keith Health Centre, Keith, Banffshire AB5 3DJ

W MELVIN MORRISON, MB, MRCGP, general practitioner

J A B MATHESON, MB, MRCGP, general practitioner

R B HUTCHISON, MB, MRCGP, general practitioner

R H MACK, MB, MRCGP, general practitioner

\section{The Rinso eaters of Groote Eylandt}

Groote Eylandt lies at $14^{\circ}$ of latitude in the upper part of the Gulf of Carpentaria and is inhabited by 1200 Aboriginal people of the Nungubyu and Wenindhagra tribes. The community has experienced several forms of experimentation with chemical hallucinogenic agents. In particular, petrol sniffing ${ }^{1}$ is practised by boys and girls among the school population. Clay eating ${ }^{2}$ is also recorded. I describe two patients who had experimented with an unusual intoxicant.

\section{Case reports}

Case 1-A 15 year old full blood Aboriginal girl presented at the Angurugu Health Centre complaining of severe generalised abdominal pain of 18 hours' duration. She had vomited once without relief from her pain. There had been no diarrhoea or bladder disturbance, and the menstrual history was uncertain. She lay in bed with legs drawn up, in obvious pain. There was no fever; pulse was $88 / \mathrm{min}$. The abdomen was described as rigid, and attempts at palpation were resisted. Rectal examination was not performed. Urine analysis showed nitrates + , ketones +++ . Her mother volunteered that her daughter had been eating soap powder by the handful. Intramuscular metoclopramide $10 \mathrm{mg}$ and hyoscine butylbromide $20 \mathrm{mg}$ were given and fluid intake actively encouraged. Mother and daughter returned next morning; the patient had vomited three times during the night and was still in pain. The physical signs were essentially unchanged, save that she was more dehydrated. A pregnancy test gave a negative result. The patient was admitted and intravenous treatment with $4 \%$ dextrose in $1 / 5$ physiological saline begun. A tentative diagnosis of acute pelvic inflammatory disease was made and ampicillin $1.5 \mathrm{~g}$ given intramuscularly. (There are no pathological facilities on the island, and neither a white cell count nor electrolyte estimation was performed.) A vaginal swab was taken. Emergency aerial evacuation to the base hospital at Nhulunbuy was considered. Next day she was greatly improved and took her own discharge as soon as the intravenous treatment was discontinued. She was visited by an Aboriginal health worker the following day and claimed to be quite recovered. She gave up eating soap powder and remained well.

Case 2-A 16 year old full blood Aboriginal girl attended the health centre on account of severe generalised abdominal pain and severe nausea. There had been no diarrhoea, vomiting, or urinary disturbance, and the last period had finished six days before. There was no fever; pulse was $96 / \mathrm{min}$. The abdomen showed generalised tenderness with guarding in the epigastrium. Bowel sounds were very active. Urine analysis yielded ketones +++ . Gastroenteritis was diagnosed and intramuscular metoclopramide and dipyrone given after her admission for observation. Fluid intake was encouraged. Next morning her condition had improved and she was allowed home. The following day she offered the information that she had been eating Rinso before being taken ill. She discontinued this practice and remained well.

\section{Comment}

These patients turned out to be high spirited chums at school. Not to be outclassed by their petrol sniffing companions, they had adopted the practice of eating soap powder to obtain a "buzz" or "high." The patients were members of a larger coterie, who met socially to enjoy their "scene." After experimentation their group had agreed that Rinso was the preferred product. Both patients closely mimicked the signs of acute pelvic peritonitis and became ketotic. Rinso contains $20 \%$ sodium carbonate, a $1 \%$ solution has a $\mathrm{pH}$ of 10.9 , and the $\mathrm{LD}_{50}$ (oral) for mice is $3 \mathrm{~g} / \mathrm{kg}$. A toxic dose for an adult patient would be of the order of $200 \mathrm{~g}$. One handful of Rinso weighs about $40 \mathrm{~g}$.

(1)

.


The recommended first aid is to remove powder from the mouth, give water or milk, observe for foam inhalation, and do not give acid substances.

The manufacturers state that they know of no previous cases despite the global distribution of this product.

I thank the Aboriginal health workers and Sister Rachel Jordan for their help, and J Hole, Lever and Kitchen, Sydney, for the technical information.

${ }^{1}$ Eastwell HD. Petrol inhalation in Aboriginal towns. Med $\mathcal{F}$ Aust 1979;ii : 222-4.

${ }^{2}$ Bateson EM. Clay eating by Aboriginals of the Northern Territory. Med $\mathcal{F}$ Aust $1978 ; 1$ special supplement No I:1-3.

(Accepted 8 December 1982)

East Arnhem Region, NT 5797, Australia

DAVID S WATSON, MB, FRACGP, regional medical officer

\section{Intraperitoneal hydrocortisone in eosinophilic peritonitis associated with continuous ambulatory peritoneal dialysis}

Eosinophilic peritonitis occurs in a small but notable number of cases of culture-negative peritonitis in patients treated with continuous ambulatory peritoneal dialysis. The diagnostic feature is a high eosinophil count in the effluent dialysate which is often associated with peripheral eosinophilia. ${ }^{1-3}$ The incidence of this condition has risen recently as differential white cell counts of the dialysate are routinely performed in investigating culture-negative peritonitis in patients undergoing continuous ambulatory peritoneal dialysis. We report such a case which responded promptly to treatment with intraperitoneal hydrocortisone.

\section{Case report}

A 57 year old woman with chronic renal failure secondary to polycystic kidney disease began treatment with continuous ambulatory peritoneal dialysis. She also had chronic obstructive airways disease and allergy to house dust and camel hair, for which she was treated with salbutamol, ipratropium inhalers, and vitamin supplements. Two days after a Tenckhoff peritoneal catheter had been inserted and one day after she had begun dialysis she developed peritonitis with a turbid effluent dialysate, low grade pyrexia, and mild abdominal tenderness. Repeated microbiological cultures-for anaerobes, tubercle bacilli, and fungi-were all negative despite a consistently raised dialysate white cell count $>1 \times 10^{9} / 1\left(>1000\right.$ cells $\left./ \mathrm{mm}^{3}\right)$. The initial symptoms persisted and she developed hypoalbuminaemia, oedema, and postural hypotension. Several courses of intraperitoneal antibiotics, including cephalothin, gentamicin, and vancomycin, were ineffective, and intravenous infusions of albumin deficient in sodium were required on several occasions.

One month after the onset of peritonitis a differential white cell count on the effluent dialysate showed $80 \%$ eosinophils. Peripheral eosinophilia ( $>40 \%$ eosinophils) was also present. On the basis that the peritonitis was allergic in origin all drugs, antibiotics, and disinfectants containing iodine were stopped and the brand of dialysis fluid and tubing changed. Despite an initial improvement in the cell count a relapse occurred four weeks later. Intraperitoneal hydrocortisone was started; the initial dose of $200 \mathrm{mg}$ daily was rapidly decreased to $40 \mathrm{mg}$ daily. The peritonitis completely resolved and within a week the dialysate total white cell count fell below $0.005 \times 10^{9} / 1$ $\left(5 / \mathrm{mm}^{3}\right)$ and contained no eosinophils. Protein losses in the dialysate decreased appreciably and the serum albumin concentration rose without further albumin infusions. After nine weeks treatment with hydrocortisone was stopped, but a relapse occurred within a week. Hydrocortisone was reinstituted and complete resolution occurred both clinically and cytologically (figure).

\section{Comment}

Though eosinophilic peritonitis has occurred in association with intermittent peritoneal dialysis, ${ }^{4}$ it has only recently been reported in patients undergoing continuous ambulatory peritoneal dialysis. ${ }^{1-3}$ As in our patient the peritonitis developed shortly after insertion of the peritoneal catheter, usually within two weeks. In these reports symptoms were relatively mild or even absent, apart from a turbid

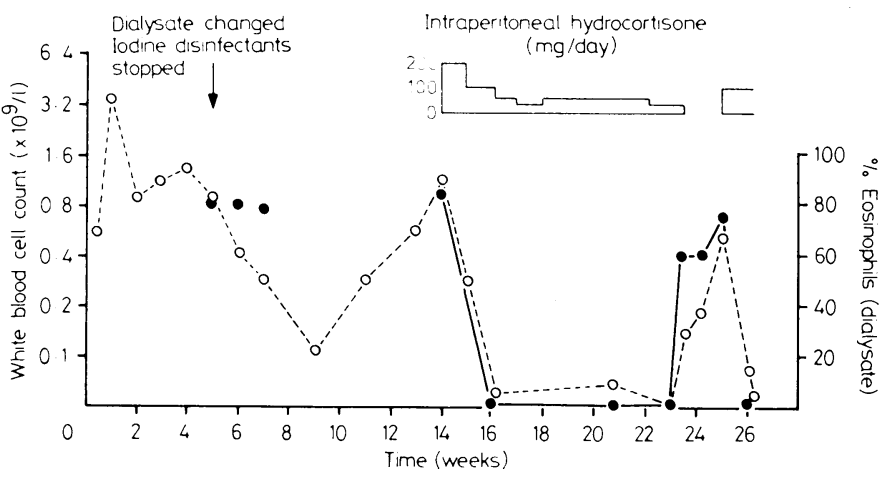

Serial white blood cell counts in peritoneal dialysis fluid: $\ldots \ldots \ldots$, white blood cells; $0, \%$ eosinophils.

effluent dialysate. Antibiotic treatment was ineffective and the diagnosis made only after repeated negative cultures and differential white cell counts of the effluent dialysate. Though most cases resolved spontaneously within two months, in some cases of intermittent peritoneal dialysis they took up to 24 months to resolve. ${ }^{4}$

Our patient appeared to have a particularly severe peritoneal eosinophilic reaction. Though changing the brand of dialysate and the antiseptics produced a partial response, the dialysate white cell count did not return to normal values. Only treatment with intraperitoneal hydrocortisone produced a normal count on two occasions.

The cause of eosinophilic peritonitis is still unclear, though peritoneal hypersensitivity to allergens-such as povidone-iodine, talc, particulate matter in the dialysate, plasticisers used in the manufacture of tubing, peritoneal catheters, or even blood from retrograde menstruation-may be responsible. ${ }^{1-5}$ Our patient had a history of atopy which may have contributed to her eosinophilic response to an unknown allergen.

Since patients undergoing continuous ambulatory peritoneal dialysis may develop culture-negative peritonitis, particularly soon after insertion of a peritoneal catheter, differential white cell counts of the effluent dialysate should be performed at an early stage. Antibiotic treatment is ineffective. In cases in which the clinical condition deteriorates and dialysis needs to be continued intraperitoneal hydrocortisone should be given in low doses after possible allergens have been carefully looked for.

${ }^{1}$ Noph KD, Sorkin MI, Prowant BF, et al. Symptomatic eosinophilic peritonitis in CAPD. Dialysis and Transplantation 1982;11:309-13.

" Gokal R, Ramos JM, Ward MK, Kerr DNS. "Eosinophilic" peritonitis in CAPD. Clin Nephrol 1981;15:328-30.

${ }^{3}$ Spinowitz BS, Golden RA, Rascoff JH, Charytan C. Eosinophilic peritonitis. In : Gahl GM, ed. Advances in peritoneal dialysis. Amsterdam Excerpta Medica, 1981:276-80.

+ Humayun HM, Ing TS, Daugirdas JT, et al. Peritoneal fluid eosinophilia in patients undergoing maintenance peritoneal dialysis. Arch Intern Med $1981 ; 141: 1172-3$

${ }^{5}$ Lasker N, Burke JF, Patchefsky A, et al. Peritoneal reactions to particulate matter in peritoneal dialysis solutions. Trans Am Soc Artif Intern Organ $1975 ; 21: 342-5$.

(Accepted 24 November 1982)

Departments of Medicine and Bacteriology, Royal Infirmary, Glasgow G4 OSF

A C T LEUNG, MRCP, registrar

G ORANGE, $M B$, registrar

I S HENDERSON, MRCP, senior registrar

THYME is a noble strengthener of the lungs, as notable a one as grows ; neither is there scarce a better remedy growing for that disease in children which they commonly call the Chin-cough, than it is. It purges the body of phlegm, and is an excellent remedy for shortness of breath. It kills worms in the belly, and being a notable herb of Venus, provokes the terms, gives safe and speedy delivery to women in travail, and brings away the after birth. It is so harmless you need not fear the use of it. An ointment made of it takes away hot swellings and warts, helps the sciatica and dullness of sight, and takes away pains and hardness of the spleen. Tis excellent for those that are troubled with the gout. It eases pains in the loins and hips. The herb taken any way inwardly, comforts the stomach much, and expels wind. (Nicholas Culpeper (1616-54) The Complete Herbal, 1850.) 